\title{
Çocuk Hastalarda Kullanılan Kuron Restorasyonlar
}

\section{Crown Restorations Used in Pediatric Patients}

\section{Ozan Üstün ${ }^{1}$ (D), Mine Koruyucu² ${ }^{\mathbb{C}}$}

\footnotetext{
1 İstanbul Üniversitesi Diş Hekimliği Fakültesi, İstanbul, Türkiye

2 İstanbul Üniversitesi, Diş Hekimliği Fakültesi, Pedodonti Anabilim Dalı, İstanbul, Türkiye

ORCID: O.Ü. 0000-0001-6158-8766; M.K.0000-0002-2077-5095
}

Sorumlu Yazar/Corresponding author: Doç. Dr. Mine Koruyucu,

İstanbul Üniversitesi, Diş Hekimliği Fakültesi, Pedodonti Anabilim Dalı, İstanbul, Türkiye E-posta: mine.yildirim@istanbul.edu.tr

Geliş tarihi/Submitted: 27.10.2020 Kabul/Accepted: 04.05.2021

Atıf/Citation: Ustun O, Koruyucu M. Crown restorations used in pediatric patients. Sağlık Bilimlerinde İleri Araştırmalar Dergisi 2021; 4(3): 113-123.

https://doi.org/10.26650/JARHS2021-817099
ÖZ

Çocuklarda ağız hijyeni ilk diş sürmeye başladığı andan itibaren önemlidir. Ağız hijyeninin sağlanması için gerekli özen gösterilmediğinde çürük görülme riski artmaktadır. Çocuklarda koruyucu tedavilerden başlanarak kuron restorasyonlarına kadar uzanan geniş yelpazede bir tedavi çeşitliliği bulunmaktadır. Kuron restorasyonları, aşırı madde kaybı bulunan dişlerin kaybını önlemek için yapılan en önemli tedavi yöntemlerinden biridir. Çocuk hastalarda estetik ihtiyaca, dişin durumuna ve maddi duruma göre endikasyon koyulduktan sonra seçilecek tedavi yöntemine uygun olarak değişik kuron restorasyonları (paslanmaz çelik kuronlar ve zirkonyum kuronlar v.b) bulunmaktadır. Çocuk hastalarda süt dişinin ağızda kalma süresinin yetişkin hastalarla kıyaslandığında çok daha kısa olması, süt dişi tedavilerinde kuron restorasyonlarının tercih edilme sıklığının az olmasına neden olmaktadır. Ancak günümüzde çocuklar ve ebeveynlerin fonksiyon ve estetik açıdan süt dişlerinin önemini kavramaları bu gibi tedavilerin uygulama oranlarını arttırmıştır. Bu derlemede, çocuk hastalarda uygulanan kuron restorasyonlarının endikasyonları ve kullanım alanları anlatılmıştır.

Anahtar kelimeler: Çocuk diş hekimliği, Kuron, Restorasyon

\section{ABSTRACT}

Oral hygiene is important from the very first tooth eruption in children. The risk of caries increases when the necessary care is not taken to ensure oral hygiene. There is a wide range of treatments in children, ranging from preventive treatments to crown restorations. Crown restorations are one of the most important treatment methods to prevent the loss of teeth with excessive material loss. There are different crown restorations (stainless steel crowns and zirconium crowns etc.) in pediatric patients according to the aesthetic need, the condition of the tooth and the treatment method to be selected after the indication is placed. Due to the short life of the primary teeth in pediatric patients, the frequency of this treatment is less than in adult patients. Nowadays, children's and parents' understanding of the importance of primary teeth in terms of function and aesthetics has increased the application rates of such treatments. In this review, the indications and usage areas of crown restorations applied in pediatric patients are explained.

Keywords: Pedodontics, Crown, Restorations 


\section{GİRIŞ}

Diş çürügü, gelişmekte olan ülkelerde \%60-90 oranlarında görünen, gelir düzeyi düşük bireylerin önemli kısmını etkileyen bir sağlık sorunudur (1). Diş çürüğü; vücuda alınan karbonhidratların bakterilerle fermente edilmesiyle ortaya çıkan asitlerin, dişlerin mine-dentin dokularında neden olduğu yıkım olarak tanımlanmaktadır (2).

Süt dişlerinde minenin, sürekli dişlere göre yapısal olarak daha farklı olması sebebiyle süt dişlerindeki çürükler sürekli dişlere göre daha hızlı ilerlemektedir (3). Tedavisi yapılmayan süt diş çürükleri hızla yayılım göstererek madde kayıplarına sebep olmakta ve birden çok yüzeyde çürük bulunan dişlerin tedavisi komplike yöntemler kullanılarak yapılabilmektedir. Süt dişlerinin çürük tedavisinde görülen başarısızlık sürekli dişlere göre daha fazla olabilmektedir. Bunların sebepleri arasında çocuklarda ağız hijyeninin sağlanmasında zorluk yaşanması, dişlerin morfolojik farklılıkları, dişlerin kimyasal yapılarının farklı olması ve yanlış materyal kullanımı olarak sıralanabilmektedir. Madde kaybı fazla olan süt dişlerinde kuron restorasyonlarının tercih edilmesi daha doğru bir yöntem olarak görülmektedir. Böylece süt dişlerinin mezio-distal boyutunun korunması, dişin yapısal bütünlüğünün korunması, biyouyumlu olması ve dişin kullanım ömrünün artması sağlanabilmektedir (4).

Amerika Çocuk Diş Hekimleri Akademisi (AAPD) çoklu yüzey çürüğü bulunan dişlerin restorasyonunda paslanmaz çelik kuronları (PÇK) önermektedir (5). Ayrıca aşırı madde kayıplı dişlerde cam iyonomer simanlar (CİS), amalgam, kompomer, strip kuron, polikarbonat kuron ve zirkonyum kuronlar da tercih edilmektedir. Bu materyaller birbiriyle karşılaştırıldıklarında ayrı avantaj ve dezavantajları bulunmaktadır. Diş hekimi her olguya özgü materyal seçimi yapmalı ve estetik, tutuculuk, dayanıklılık, alerjik etki ve maliyet gibi unsurları göz önünde bulundurmalıdır. Günümüzde, estetiği iyi olan dişler, sosyo-ekonomik olarak gelişmişlik göstergesi olarak görülmektedir (6).

Bu derlemede çocuk hastalarda uygulanan kuron restorasyonlarının endikasyonları ve kullanım alanları anlatılmıştır.
Süt dişleri, sürekli dişler sürene kadar estetik, fonasyon, fonksiyon ve yer tutma görevini karşılamaktadır. Bu yüzden süt dişinin düşme zamanı gelene kadar ağızda kalması çene gelişimi ve kalıcı dişlenme için oldukça önemlidir (7).

Süt dişleri için restorasyon işlemlerinde genel olarak sürekli dişlerle aynı prosedürler uygulanmasına rağmen bazen morfolojik ve histolojik farklılıklardan dolayı farklı tercihler yapilabilmektedir. Uygulanan estetik restorasyonlarda endikasyon, dişin yapısal özelliklerinin (pulpa yapısı, mine yapısı ve diş boyutu) yanı sıra çocuğun bilişsel ve duygusal durumu ve materyalin maliyetine bağlı olarak da değişebilmektedir $(7,8)$.

Rocky Mountain Company tarafindan ilk kez 1947 yılında kuron restorasyonlar tanitılmıştır. 1950 yılında ise Engel, paslanmaz çelik kuronları (PÇK) tanıtmış ama bunun yaygınlaşması daha çok William Humphrey ile olmuștur. 1971 yılında derin çürükler için paslanmaz çelik kuronun modifiye edilmesini diş arası boşlukların lehim ile kapatılmasını öne süren bir görüş ortaya atılmıştır. 1970’lerin sonuna doğru ise PÇK'ların yer koruma amacıyla da kullanılması görüşü ortaya atılmıştır. Webber 1979 yılında strip kuronları ortaya çıkarmıştır. 1983 yılında Hartman estetik anterior kuronlar için venerlenmiş paslanmaz çelik kuronu geliştirmiştir. 1980’lerin sonuna doğru Cheng kuronlar ve Kinder kuronlar piyasaya çıkmıştır (9). 1990'ların başında Randy ve arkadaşları paslanmaz çelik kurona loop ekleterek paslanmaz çelik kuron üzerine band loop yer tutucuyu kullanmıştır. Yine 1990'lı yılların başlarında Norna Hall diş çürügü temizlenmeden dişlerin paslanmaz çelik kuron ile restore edildiği bir teknik geliştirmiştir. Günümüze geldiğimizde ise daha iyi estetik ve materyal arayışı zirkonyum kuronları öne çıkarmıştır (10).

Aşırı madde kaybı olan dişlerin restorasyonlarında başarısızlık yüksek olduğu için kuron restorasyonu daha fazla tercih edilmektedir. Kuron restorasyonu için endikasyonları şu şekilde sırayabiliriz;

- Endodontik tedavi uygulanmış dişlerde,

- İlerlemiş ara yüz çürüklerinin tedavisinde,

- Kırık dişlerin tedavisinde, 
- Çok yüzlü çürük varlığında,

- Tedavisi genel anestezi altında yapılan çocuklarda,

- Bruksizm hastalarında,

- Servikal bölgelerdeki defektlerin tedavisinde,

- Yüksek çürük riski olan ve ve döner aletlere karş1 kooperasyon eksikliği görülen çocuklarda,

- Pulpotomi-pulpektomi tedavisi uygulanan dişlerde kullanılmaktadır.

İdeal süt dişi kuron restorasyonlarında istenilen özellikler;

- Estetik olmal1,

- Çiğneme fonksiyonu korunmalı,

- Kullanım ömrü süt dişinin ömrüne yakın olmalı,

- Kırılmaya karşı dişi korumalı,

- Antagonist dişte herhangi bir aşınmaya sebep olmamal,

- Kolay uygulanabilir olmalı,

- Kaybolan fonksiyonu geri kazandırmalıdır (10, 11).

Günümüzde süt dişlerinin tedavisinde en sık kullanılan kuron restorasyonları;

- Paslanmaz çelik kuronlar

- Polikarbonat kuronlar

- Strip kuronlar

- Pediatrik jaket kuronlar

- CAD/CAM sistemi ile oluşturulan kuronlar

- Zirkonyum kuronlardır

\section{1- Paslanmaz Çelik Kuronlar}

Çürük sebebi ile ileri derecede harabiyet oluşan süt dişlerinde restoratif tedavi her zaman doğru yanıt vermeyebilir. Bu sebeple 1950'lerin başında Dr. Humphrey paslanmaz çelik kuronları, yer tutucu ve kuron restorasyon olarak ilk defa kullanmaya başlamıştır (12). Böylece çocuklarda çekim endikasyonu sıklığı azalmış, dişler daha uzun süre ağızda kalmaya başlamıştır. Paslanmaz çelik kuronun (PÇK) içeriğinde \%12-30 arasında krom, \%8 nikel, \%1-20 arasında değișen karbon yer almaktadır. PÇK'ların kullanım ömürleri amalgamlara göre daha fazla olarak bildirilmektedir. (13).

Paslanmaz çelik kuronun endikasyonları aşağıda belirtildiği gibidir;
- Adeziv bağlantının mümkün olmadığı az miktarda mine kalmış dişler,

- Dişin birden çok yüzeyinde görülen çürük oluşumu,

- Kötü ağız hijyeni olan hastalar,

- Kanal tedavisi ve amputasyon uygulanan süt dişleri,

- Diş anomalileri varlığında,

- Süt ve sürekli dişlerde görülebilen aşırı madde kayıplı kırıklarda,

- Subgingival çürüklerde uygulanabilmektedirler (13-15).

Atieh yapmış olduğu bir çalışmada, süt azı dişlerine pulpa tedavisinden sonra uygulanan PÇK ile rezin modifiye cam iyonomer siman ve kompozit rezin kullanılan modifiye açı sandviç tekniğinin klinik başarısını ve ağızda kalma süresini karşılaştırmıştır. Yaşları 4- 7 arasında değişen 87 çocuğun yer aldığ 1 çalışmada 160 restorasyonun 6, 12, 18 ve 24 aylık kontrolleri yapılmıştır. İki senelik takipten sonra restorasyonların ağızda kalma oranları PÇK için \%95, modifiye açık sandviç restorasyonu için \%92,5 olarak belirtmiştir. İki restorasyon içinde marjinal uyum, proksimal kontak, oklüzyon ve tekrarlayan çürük kriterleri açısından anlamlı bir ayrım görülmemiştir. Dişeti sağlığı olarak incelendiğinde ise modifiye açık sandviç tekniği ile yapılmış restorasyonlarda PÇK’ya göre daha iyi sonuçlar elde edilmiştir (16).

Webber 8-12 yaş grubundaki bir grup hastada uyguladığı paslanmaz çelik kuron restorasyonlarının takibinde bir miktar diş eti büyümesi olduğunu gözlemlemiştir. Ancak karışık dişlenme döneminde diş eti farklılığının fizyolojik olabileceğinin ve kuronun kullanım süresinin diş eti dokuları üzerinde önemli bir etkisi olmadığını bildirmiştir (17). Sharaf ve Farsi ise PÇK’nın ara yüz kontağının olmamasının diş eti sağlı̆̆ı üzerinde bir etkisinin olmadığını belirtmişlerdir. Paslanmaz çelik kuronların etrafındaki diş eti sağlığı için en belirgin etkenin ağız hijyeni seviyesi olduğunu bildirmişlerdir (18).

Papathanasiou ve arkadaşları, farklı restoratif materyallerin klinik başarısını değerlendirmişlerdir. Toplamda 604 restorasyonun incelendiği bu çalışma- 
da, uygulanan restorasyonların ağızda kalma sürelerinin, yüksekten düşüğe doğru sırasıyla PÇK, amalgam, kompozit rezin ve cam iyonomer siman olduğu belirtilmiştir. PÇK ve amalgam restorasyonlarının ortalama ağızda kalma süresinin 5 sene olduğu bildirilmiştir. Bu süre içinde PÇK'ların ağızda kalma yüzdesi \%68, amalgam restorasyonun ise \%60'tır. Dört sene sonrasinda, kompozit rezin restorasyonların başarı yüzdesinin $\% 40$ ve ortalama ağızda kalma sürelerinin 32 ay olduğu; cam iyonomer siman restorasyonların başarı oranlarının $\% 5$ ve ortalama ağızda kalma süresinin 12 ay olduğu belirtilmiştir (19).

Paslanmaz çelik kuronların (dezavantajları olarak silinecek), diş eti uyum sorunu olduğunu ya da (ağız içindeki durumuna bakarak) periodontal soruna neden olabileceğini belirten çalışmalar mevcuttur. Hekimin klinik deneyiminin yetersiz olması ya da dişte fazla kesim yapıldığı durumlarda da diş kayıpları görülebilmektedir. Sadece ön bölge süt dişlerinde değil arka bölge süt dişleri için de paslanmaz çelik kuronların estetik özelliği önemli bir dezavantaj olarak ortaya çıkmaktadır. Bu olumsuz özelliği giderebilmek için açık yüzlü paslanmaz çelik kuron ve venerlenmiş paslanmaz çelik kuronlar geliştirilmiştir (20).

\section{2- Açık Yüzlü Paslanmaz Çelik Kuronlar}

Estetik özelliklerin yetersiz olması, ebeveyn ve çocuklar tarafından kabul görmemesine karşın mevcut dişin ağızda korunması için PÇK'lar günümüze kadar kullanılmaya devam etmiştir. Teknolojinin ilerlemesi ile birlikte paslanmaz çelik kuronların estetikleri geliştirilmeye çalışılmıştır. Açık yüzlü paslanmaz çelik kuronlar klinikte uyguladığımız paslanmaz çelik kuronların ön yüzünün kaldırılıp kaldırılan bölüme rezin yerleştirilmesiyle elde edilir. İlk olarak 1980’lerin başında kullanılmaya başlanmıştır (21). Nagarathna ve arkadaşlarının yaptığı anket çalışmasında, katılan hekimlerin \%70'i çok yüzlü çürük durumuyla karşılaştıklarında ön bölgeye açık yüzlü paslanmaz çelik kuron yapabileceklerini belirtmişlerdir. İlave olarak hekimler, uygulama kolaylığının bir avantaj olmasının yanında, çocuk-ebeveynlerin bu durumdan memnun olduğunu belirtmiştir. Çocukların \%81,8'i tedavi süresince olumlu etkileşim göstermişlerdir (22).
Açık yüzlü paslanmaz çelik kuronların dezavantajları; tedavi süresinin uzun olması, oklüzal kuvvetlere bağlı olarak kırılmalar gözükmesi ve estetik olarak yeterli olmaması olarak belirtilmektedir (23).

\section{3- Venerlenmiş Paslanmaz Çelik Kuronlar}

Açık yüzlü paslanmaz çelik kuronlarda karşılaşılan problemler sebebiyle alternatif olarak venerlenmiş paslanmaz çelik kuronlar geliştirilmiştir. Venerlenmiş paslanmaz çelik kuronlar hastanın ağzında herhangi bir şekilde hazırlık işlemi gerekmeksizin simante edilebilen estetik görünümlü kuron çeşididir. İlk başlarda ön bölge süt dişlerinde kullanılmaya başlanmış olup ileriki zamanlarda arka bölge süt dişleri için de uygulanmıştır. Bu kuronlar tek bir randevu süresinde uygulanmakta ve tükürük ortamından daha az etkilendiği bildirilmektedir. Estetik bölümler üretici tarafından yapıldığ $\breve{1}_{1}$ icin hekimin hastaya harcadığ süre de azalmıştır (24).

Venerlenmiş paslanmaz çelik kuronların dezavantajları;

- Konturlama sirasında fasiyal yüzeylerde kırılma olabileceğinden konturlama işlemi sadece palatinal/ lingual yüzeye yapılmaktadır,

- Renk seçenekleri sınırlıdır bu yüzden doğal görüntü yakalanması zordur,

- Yer darlığı olan çocuklarda uygulanması hacim genişliği sebebiyle zordur,

- Diş yapısına pasif oturması sebebiyle daha fazla diş kesimi yapılmaktadır $(24,25)$.

Fuks ve arkadaşları, venerlenmiş paslanmaz çelik kuronlarla, geleneksel paslanmaz çelik kuronların klinik başarısını 6 aylık süreçte karşılaştırılmalı olarak incelemiştir. Çalışma sonunda, kuron kenarının uyumlu, kuronların uygun pozisyonda/oklüzyonda olduğu, proksimal kontağın sağlandığı, kemikte rezorpsiyonun gözükmediği ve venerlenmiş paslanmaz çelik kuronların estetik kısmında herhangi bir kırılma veya deformasyon gözlenmediği rapor edilmiștir. Venerlenmiş paslanmaz çelik kuronlarda, paslanmaz çelik kuronlara göre anlamlı derecede farklı dişeti uyumsuzluğu olduğunu belirtmişlerdir (26). Shah ve arkadaşları, 12 çocuk hastada ön bölgede uyguladıkları 46 venerlenmiș PÇK’yı incelemișlerdir. Kuron 
uygulanan dişlerin ortalama ağızda bulunma sürelerinin 17,5 ay (5-38 ay arası) olduğunu belirtmişlerdir. Kuronların \%24'ünde rezin kırığı gözlenmediği, \%61'inde herhangi bir kırılma görülmediğini bildirmişlerdir. Kuron uygulaması yapılan dişlerin dişetleri incelendiğinde, dişlerin \%61'inde gingival sağllğın iyi olduğu, \%24'ünün dişeti bölgesinde kızarıklık, \%15'inde spontan kanama görüldüğünü rapor etmişlerdir (27).

\section{4- Polikarbonat Kuronlar}

1970'lerden itibaren yaygin olarak kullanılmaya başlayan polikarbonat kuronlar akrilik rezinin ısı ile sertleşmesi sonucu prefabrike olarak üretilmektedir. Fabrikasyon üretim sonucu self cure akrilik rezinden daha ince olarak üretilmektedir. Paslanmaz çelik kurondan estetik olarak daha iyi olmasına karşın kırılganlık ve kolay aşınmaları sebebiyle popülerliklerini kaybetmişlerdir (28).

Polikarbonat kuron uygulanırken prepare edilmiş dişe uygun prefabrike polikarbonat kuron seçilir ve uyumlandırma sonrası dişe akrilik rezin ile yapıştırilır. Marjinler düzeltilip polisaj yapılarak restorasyon tamamlanır. Polikarbonat kuronlarda kırılma ve dişten bütünüyle ayrılma olabileceği unutulmamalıdır. Bu yetersizliği nedeniyle kullanımları çok azdır (28).

Polikarbonat kuronlar endikasyonları paslanmaz çelik kurona benzemesine rağmen kontraendike olduğu durumlar da bulunmaktadır. Bunları şu şekilde siralayabiliriz;

- Derin kapanış olan olgularda,

- Kökte ilerleyen rezorpsiyon varlığında,

- Aşırı diş aşınması ya da bruksizm vakalarında,

- Aşırı madde kaybı görülen dişlerde,

- Periodontal hastalık durumlarında,

- Çapraz kapanışın görüldüğü durumlarda,

- Derin kapanış olgularında kontraendikedir (29,30).

\section{5- Strip Kuronlar}

Strip kuronlar 1970'li yılların sonlarından itibaren süt dişlerinin restorasyonlarında sıklıkla kullanılmıştır. Bonding ajanların geliştirilmesi ve kompozitlerin mine-dentine bağlanabilme kapasitesinde artış ile aşırı harap olmuş ön-arka bölgedeki süt dişlerinin tedavisinde, diş formunu, fonksiyonu ve estetiği elde etmek amaciyla strip kuronlar geliştirilmiştir (31). Özellikle aşırı madde kaybı olan ön grup süt dişlerinde yıllardır kullanılan paslanmaz çelik kuronların yerine estetik açıdan çok daha iyi olan ve geniş kullanım alanı bulunan strip kuronlar tercih edilmektedir. Paslanmaz çelik kuronlara alternatif olarak arka bölge dişler için de strip kuronlar üretilmiş ancak paslanmaz çelik kuronlar kadar yaygın uygulama alanı bulmamıştır. Strip kuronlar, plastik diş formundaki uygun kalıbın uygulanacak diş için seçimi ve çürük temizlendikten sonra kuronun adaptasyonu ile diş rengindeki bir restorasyon materyali ile tüm dişin restore edilmesi esasına dayanmaktadır. Rezin materyali, uygun şekillendirme yapıldıktan sonra ışık cihazı ile sertleştirilir. Bundan sonra plastik diş formu çıkarılır ve diş üzerindeki kalan kısım düzeltilerek polisaj yapılmaktadır (32).

Strip kuronun avantajları; estetik özelliğinin iyi olması, parlak ve pürüzsüz bir yüzey elde edilebilmesi, ekonomik olması, doğal görüntüye oldukça benzer sonuç elde edilebilmesi, kolay ve hızlı bir şekilde uygulanabilmesidir (33).

Tate ve arkadaşları, genel anestezi ile tedavi edilen süt dişlerinin restorasyon başarılarını araştırdığı retrospektif çalışmada, 504 hastanın kayıtlarını incelemiş ve PÇK'ları amalgam, kompozit, strip kuron gibi restoratif yöntemlere göre anlamlı derecede başarılı bulmuşlardır. PÇK’larda görülen başarısızlık \%8 iken, strip kuronların ki \%51 olarak bildirilmiştir (34).

Strip kuronların uygulaması sırasinda hassas bir teknik kullanmak gerekmektedir. Materyale iyi şekil ve uygun renk verilebilmesi için kan ve tükürük ile kontaminasyonunun engellenmesi önem taşımaktadır. Bonding materyalinin ve kompozitin uygun bağlanabilmesi için preparasyon sonrasında kalan diş dokusunun yeterli miktarda olması gerekmektedir. Aynı zamanda strip kuronların çok küçük yaştaki çocuklara -kooperasyon problemlerinden dolayı -uygulanmas1 zor olabilmektedir $(33,35)$.

\section{6- Pediatrik Jaket Kuronlar}

Şiddetli çürük ya da travma sonrası kullanılan alternatif bir kuron çeşididir. Kopolyester içerikli, 
Tablo 1. Pediatrik kuronların avantaj ve dezavantajları

\begin{tabular}{|c|c|c|}
\hline & Avantaj & Dezavantaj \\
\hline Paslanmak Çelik Kuronlar & $\begin{array}{l}\text { - uygun okluzal kapanış sağlanır } \\
\text { · kapanış ilişkileri korunur } \\
\text { - kontur ve marjinal uyum sayesinde } \\
\text { periodontal problemler önlenir } \\
\text { · canlı dişlerde pulpa korunur } \\
\text { - mezio-distal diş boyutu ve ark uzun- } \\
\text { luğu korunur } \\
\text { - kullanım ömrünü uzundur } \\
\text { - restorasyon sirasinda ve sonrasında } \\
\text { hasta uyumu iyidir }\end{array}$ & $\begin{array}{l}\text { - dişeti uyum sorunu ve } \\
\text { - periodontal soruna neden olabilir } \\
\text { · dişte fazla kesim yapıldığı durumlarda da diş } \\
\text { kayıpları görülebilir } \\
\text { - estetik özelliği iyi değildir }\end{array}$ \\
\hline Açık yüzlü PÇK & $\begin{array}{l}\text { · PÇK olarak ön bölgede kullanım } \\
\text { imkanı sunmuştur } \\
\text { · tek seansta uygulanabilir }\end{array}$ & $\begin{array}{l}\text { · hasta ağızında hazırlık işlemi gerektirmektedir } \\
\text { · tedavi süresinin uzundur } \\
\text { · oklüzal kuvvetlere bağlı olarak kırılmalar gözükür } \\
\text { · estetik olarak yeterli değildir }\end{array}$ \\
\hline Venerlenmiş PÇK & $\begin{array}{l}\text { · hastanın ağzında herhangi bir şekil- } \\
\text { de hazırlık işlemi gerekmez } \\
\text { · estetik görünümlüdür } \\
\text { · tükürük ortamından daha az etki- } \\
\text { lenmektedir } \\
\text { · hekimin hastaya harcadığı süre } \\
\text { azalmıştır }\end{array}$ & $\begin{array}{l}\text { - konturlama sırasında fasiyal yüzeylerde kırılma } \\
\text { olabileceğinden konturlama işlemi sadece palatinal/ } \\
\text { lingual yüzeye yapılmaktadır } \\
\text { · renk seçenekleri sınırlıdır bu yüzden doğal görün- } \\
\text { tü yakalanması zordur } \\
\text { · yer darlığı olan çocuklarda uygulanması hacim } \\
\text { genişliği sebebiyle zordur } \\
\text { · diş yapısına pasif oturması sebebiyle daha fazla diş } \\
\text { kesimi yapılmaktadır }\end{array}$ \\
\hline Polikarbonat Kuronlar & $\begin{array}{l}\text { - estetik olarak iyidir } \\
\text { - retansiyonun geliştirebilir } \\
\text { - esnektir } \\
\text { - iyi bir adaptasyon sağlanır }\end{array}$ & $\begin{array}{l}\text { - kolay kırılabilir } \\
\text { · renk değişimi gözlenebilir } \\
\text { · tutuculuk bakımından sınırlıdır }\end{array}$ \\
\hline Strip Kuronlar & $\begin{array}{l}\text { - estetik özelliğinin iyidir } \\
\text { - parlak ve pürüzsüz bir yüzey elde } \\
\text { edilebilir } \\
\text { · ekonomikdir } \\
\text { · doğal görüntüye oldukça benzer } \\
\text { sonuç elde edilebilir } \\
\text { - kolay ve hızlı bir şekilde uygulana- } \\
\text { bilir }\end{array}$ & $\begin{array}{l}\text { · hassas bir teknik gerektirir } \\
\text { · kan ve tükürük ile kontaminasyonunun engelleme- } \\
\text { si gerekmektedir } \\
\text { · bonding materyalinin ve kompozitin uygun bağ- } \\
\text { lanabilmesi için preparasyon sonrasında kalan diş } \\
\text { dokusunun yeterli miktarda olması gerekmektedir } \\
\text { · çok küçük yaştaki çocuklara kooperasyon prob- } \\
\text { lemlerinden dolayı uygulanması zor olmaktadır }\end{array}$ \\
\hline Jaket Kuronlar & $\begin{array}{l}\text { · hazırlıkların bir kısmı ağız dışında } \\
\text { yapılabilir } \\
\text { · ağız içi çalışma süresi azalır } \\
\text { · kooperasyon eksikliği olan çocuklar- } \\
\text { da kullanımı nispeten daha kolaydır }\end{array}$ & $\begin{array}{l}\text { - okluzal kuvvetler ile aşınma gerçekleşebilir } \\
\text { - zamanla renk değiştirebilir } \\
\text { · kuronun simandan ayrılması görülebilir }\end{array}$ \\
\hline CAD-CAM Kuronlar & $\begin{array}{l}\text { - estetiktir } \\
\text { - ağız içinde çalışma süresi kısadır } \\
\text { · tek seansta tedavi tamamlanır } \\
\text { · klasik teknikle ölçü alınmasına gerek } \\
\text { olmadığı için çocuklarda uygulanma- } \\
\text { sı kolaydır } \\
\text { · ölçü hatalarını minimuma indir- } \\
\text { miştir }\end{array}$ & $\begin{array}{l}\text { - pahalı bir tekniktir } \\
\text { - bilgisayar ve yazılım gibi ekstra ekipman gerektirir } \\
\text { - teknik detay bilgisi gerektirir }\end{array}$ \\
\hline Zirkonyum kuronlar & $\begin{array}{l}\text { - tek seansta uygulanabilir } \\
\text { - daha estetiktir } \\
\text { - biouyumludur } \\
\text { - sterilizasyon yapılabilir } \\
\text { - dayanıklidır } \\
\text { - nikel alerjisi olanlara alternatiftir } \\
\text { - biofilm oluşumu zordur }\end{array}$ & $\begin{array}{l}\text { - eğilip bükülmesi zordur } \\
\text { - sinırlı renk seçeneği vardır } \\
\text { - teknik hassasiyet gerekir } \\
\text { - tükürük ve kanama kontrol altına alınmalıdır } \\
\text { · yer darlığ durumunda uygulaması zordur } \\
\text { - pahalıdır } \\
\text { · PÇK’ya göre daha fazla diş kesimi gerektirir }\end{array}$ \\
\hline
\end{tabular}


Tablo 2. Pediatrik kuronların karşılaştırılması

\begin{tabular}{|c|c|c|c|c|c|c|c|c|}
\hline & PÇK & $\begin{array}{c}\text { Açık yüzlüi } \\
\text { PÇK }\end{array}$ & $\begin{array}{l}\text { Venerlenmiş } \\
\text { PÇK }\end{array}$ & $\begin{array}{c}\text { Polikarbonat } \\
\text { Kuronlar }\end{array}$ & $\begin{array}{c}\text { Strip } \\
\text { Kuronlar }\end{array}$ & $\begin{array}{c}\text { Jaket } \\
\text { Kuronlar }\end{array}$ & $\begin{array}{l}\text { CAD-CAM } \\
\text { Kuronlar }\end{array}$ & $\begin{array}{c}\text { Zirkonyum } \\
\text { Kuronlar }\end{array}$ \\
\hline $\begin{array}{l}\text { Seans } \\
\text { uzunluğu }\end{array}$ & ++ & +++ & ++ & ++ & ++ & ++ & + & ++ \\
\hline Diş kesimi & ++ & ++ & +++ & ++ & + & +++ & ++ & +++ \\
\hline $\begin{array}{l}\text { Ön bölge } \\
\text { kullanım }\end{array}$ & - & + & + & + & ++ & + & ++ & ++ \\
\hline $\begin{array}{l}\text { Arka bölge } \\
\text { kullanım }\end{array}$ & ++ & + & + & + & + & ++ & +++ & ++ \\
\hline Dayanıklılık & +++ & - & + & - & ++ & + & ++++ & +++ \\
\hline Estetik & - & + & ++ & + & +++ & + & ++++ & ++++ \\
\hline Maliyet & + & ++ & +++ & ++ & + & ++ & +++++ & +++++ \\
\hline
\end{tabular}

esnek yapıda, doğal diş renginde kuronlardır. Makasla kesilerek şekillendirilebilmektedirler. Hazırlıklarının bir kısmının ağız dışında yapılabilmesi sayesinde ağız içi çalışma süresinin azalması özellikle kooperasyon eksikliği olan çocuklarda kullanımı sırasında önemli avantaj sağlamaktadır. Prepare edilen dişe asit ve bonding ajan uygulanarak yerleştirilmektedirler. İzolasyon sağlanabiliyorsa kompozit rezin simanı ile, sağlanmıyorsa rezin modifiye cam iyonomer siman ile jaket kuron dişe adapte edilir ve simantasyon gerçekleştirilir. Pediatrik jaket kuronun dezavantajları arasında okluzal kuvvetler ile aşınması ve zamanla renk değiştirmesi sayılabilir. Başarısızlık sebebi genelde kuronun simandan ayrılmasıdır. Kopolyester kuron ayrıldığı zaman yapıştırıcı olarak uygulanan kompozit veya rezin modifiye cam iyonomer siman diş üzerinde kalmakta ve yeniden restore edilmesine gerek duyulmadan bir kuron gibi görülmektedir (36).

\section{7- CAD/CAM ile Oluşturulan Kuronlar}

Aşırı madde kayıpları görülen süt dişlerinin oklüzyona kazandırılması için günümüze kadar birçok restoratif materyal kullanılmış olup ancak hem dayanıklılık hem de estetik açıdan tüm beklentileri karşılayan bir materyal ortaya çıkarılamamıştır. Mevcut kuronların dezavantajlarının olması, teknolojik gelişmelere göre paralel olarak daha pratik hazırla- nabilen ve uygulanabilen, estetik görünümü çok daha iyi olan kuronların üretilmesi ihtiyacı ortaya çıkmıştır. Günümüzde, bilgisayar destekli tasarıma ve üretime dayalı olarak hazırlanan kuronların kullanımı ön plana çıkmaya başlamıştır. Bu sistemin temelini; verilerin bilgisayar ortamında toplanması, üç boyutlu modelin oluşturulması, bu verilerin ışığında tasarımların gerçekleştirilmesi ve gerçekleştirilen tasarımlar ile üretimin yapılması oluşturmaktadır. Bilgisayar destekli şekillendirme/bilgisayar destekli üretilen restorasyonlar, Computer Assited Design/ Computer Asisted Manufacture (CAD/CAM) olarak adlandırılmaktadır. CAD/CAM teknolojileri diş hekimliği dünyasına 1980'li yıllarda tanıtılmıştır. O günden günümüze kadar bu teknolojiler ilerleme göstermeye devam etmiştir. Günümüzde CAD/CAM sistemleri inley, onley, laminate vener, bölümlü kuron, tam kuron ve köprü sistemleri gibi endikasyon alanı kapsamaktadır. CAD/CAM restorasyonları çocuk diş hekimliği klinik pratiğinde de kullanılmaya başlansa da araştırmalar dişında süt dişlerinin restorasyonlarında henüz kullanımları yaygın değildir (37).

CAD/CAM restorasyonlarının üretim maliyetinin yüksek olması, ekipmanlarının kullanılabilmesi için tecrübeli elemana ihtiyaç duyulması, subgingival s1nırı derin olan dişlerin bilgisayar ortamına aktarılmasının zor olması gibi sebeplerle günümüzde kullanım sıklığı azdır (38). 
CAD/CAM teknolojisi, restorasyon ve koruyucu diş preparasyon konseptleri birlikte düşünülmelidir. Böylece diş sert dokusunda gerekli olmayan bir uzaklaştırma yapılmasının önüne geçilip, çok daha uyumlu ve çok daha iyi işlenmiş olan restorasyonlar, tek seansta ve restorasyon yapılacak olan dişe özgü olarak elde edilebilmektedir (39). Süt azı dişlerınde CAD/CAM yöntemi ile hazırlanan kuronun in vitro şartlarda karşılaştırıld1ğı bir çalışmada; süt azı dişlerinin yaygin kuronal harabiyeti söz konusu ise polimerik CAD/CAM rezin bloklar kullanılarak Chairside Economical Restorations of Esthetic Ceramic 3 (CEREC) sistemi ile hazırlanan tam koronal restorasyonların hem estetik olmaları, hem hazırlanma maliyetlerinin düşük olması hem hasta başında ve tek seansta hazırlanabilmesi sebebiyle tercih edilebileceğini bildirilmiştir (37).

\section{8- Pediatrik Zirkonyum Kuronlar}

Zirkonyum, sembolü Zr olup, atom ağırlığ 40 olan 18.yüzy1lda Sri Lanka'da bulunan kimyasal bir elementtir. Zirkonyumun mineralleri, zirkonyum silikat ve zirkonyum oksitdir. Zirkonyum silikata zirkon, zirkonyum oksite ise zirkonya da denilmektedir. Zirkonyum doğada saf halde görülmediği ancak birçok farklı bileşik halinde bulunabildiği bildirilmiştir. Zirkonyum; sıcaklığa, aşınmaya ve korozyona karşı oldukça dayanıklı bir yapıdır. Zirkonyum metalinin saflığı, mekanik özelliklerini arttırmaktadır. Zirkonyum reaktif bir metal olduğu için, hava veya solüsyon ile temas ettiğinde yüzeyinde oksit tabakası oluşmaktadır. Oluşan oksit tabaka zirkonyumun korozyona karşı dirençli olmasını sağlamaktadır. Zirkonyumun fiziksel özelliklerinin diğer seramiklere bakıldığında çok daha üstün olduğu görülmüştür. Zirkonyumun biyomateryal olarak kullanılmaya 1969 yılında Hellmer ve Driskell'in kalça protezi yapımı ile başladığı bilinmektedir (40).

Günümüzde, süt azı dişlerinin tedavisinde kullanılabilecek en sağlam ve dişin yapısını en çok koruyabilen restorasyonların paslanmaz çelik kuronlar olduğu bildirilmektedir. PÇK’nın birçok olumlu özelliğine karşın, zayıf estetik özelliği yüzünden araştırmacılar yeni materyaller geliştirmeye devam etmektedir. Son dönemde süt dişlerinin restorasyonunda var olan ek- siklikleri gidermek, çocukların ve ebeveynlerin estetik ihtiyacını karşılamak adına zirkonyum kuronlar üretilmiștir. Bu materyaller, hem süt kesici hem de süt azı dişlerinin tedavisinde kullanılabilmektedir.

Prefabrike zirkonyum kuronlar ilk defa 2008 y1lında EZ-Pedo ${ }^{\text {та }}$ (Loomis, California, USA) markası ile piyasaya çıkmıştır. Paslanmaz çelik kuronda diş etinden metalin yansıması, renk uyumsuzluğu, yapay bir görüntünün olması, yetişkinlerde olduğu gibi estetik beklentiyi karşlayabilecek kişiye özel bir kuron olmaması yeni bir materyal üretme arzusunu doğurmuștur. Zir-Lock retansiyonu adı verilen patentli bir sistemle kuronun içine mekanik tutuculuk sağlayan oluklar açılmış ve klinik başarıyı arttırmayı hedeflemişlerdir. Çürük sebebi ile mesio-distal boyutu azalan birinci ve ikinci süt azı dişleri için daraltılmış kuronlar üretmişlerdir. Daha sonra BruxZir (Glidewell), Lava ${ }^{\mathrm{rm}}$ Premium (3M ESPE; Katana ML, Kuraray) ve NuSmile (Huston, TX, USA ) gibi firmalar tarafından çeşitli özellikte pediatrik zirkonyum kuronlar üretilmiştir (41).

Yitriyum oksitle kararlı hale gelmiş olan tetragonal zirkonyum oksit polikristalleri (yttria-stabilized tetragonal zirconia polycrystal: Y-TZP), bir kristal fazdan diğerine geçerek çatlak oluşumunu durduran, çatlağın çoğalmasını engelleyen dirençli bir yapı oluşturmaktadır. Zirkonyum materyalinin kırılma dirençlerinin yüksek olması dolayısıyla zirkonyum kuronlar oldukça güçlüdürler (42). Çocuklar için piyasaya sürülen zirkonyum kuronların hazır formu, mine yapısından çok daha kuvvetli ve çok daha dayanıklı olarak geliştirilmiştir. Zirkonyum kuronlarının saydamlığ 1 "translusent" özelliği sayesinde çok iyi estetik ve pulpal tedavi sonrası dişlerde gözüken renk problemini çözmeye olanak sağlamaktadır (43).

Holsingerve arkadaşları, ön bölge dişlerde kullanılan pediatrik zirkonyum kuronların klinik başarısını ve ebeveyn memnuniyetini inceledikleri bir çalışmada kuronları klinik olarak; tutuculuğuna, gingivale etkisine, rengine, konturuna, kenar uyumuna ve karşı dişte yarattı̆̆ abrazyona göre değerlendirmişlerdir. Ortalama 21 aylık takip sonucunda yapılan kontrollerde; kuronların hiçbirinde tutuculuk kaybının gözlenmediği, \%96'sının ağız içinde mevcut olduğu görülmüştür. Gingival indekste 
herhangi bir enflamasyon gözlenmediği belirtilmiş (\%96), \%86'sinda herhangi bir kenar uyumu problemi gözlenmemiş olup, komşu diş ile olan renk farkının (\%64) fark edilemeyecek derecede az olduğunu, zirkonyum kuron uygulanan dişte sekonder çürük oluşmadığını ve karşıı diş ile herhangi bir aşınma olmadığını bildirmişlerdir. Ebeveynler aynı zamanda pediatrik zirkonyum kuronlar uygulanan dişte, doğal diş görünümünün (\%89) olduğunu bildirmiş; çocuk ve de ebeveynlerin görsel olarak memnun oldukları belirlenmiştir (44).

Cazaux ve arkadaşları, yayınladıkları olgu raporunda birinci süt azı dişine pulpotomi sonrası EZ-Pe$\mathrm{do}^{\mathrm{Tw}} / \mathrm{EZCrown}^{\mathrm{Tw}}$ pediatrik zirkonyum kuronlar uygulamışlar ve diş eksfoliye olana kadar (29 ay) takiplerini yapmışlardır. Simantasyondan 3 gün sonra dişeti dokularının eski sağlığı ve görüntüsüne kavuştuğunu, takip süresince karşıt dişte aşınma gözükmediğini, pediatrik zirkonyum kuron uygulanan dişin simetrik dişle aynı zamanda (2 hafta farkla) eksfoliye olduğunu bildirmişlerdir. Bununla birlikte araştırmacılar klinik pratikte yeni materyalleri uygulamanın çoğu zaman kolay olmadığını, pediatrik zirkonyum kuronların ilk kullanımda, uygulama süresinin paslanmaz çelik kuronlara göre daha fazla olduğunu, zaman içerisinde klinik pratik kazanıldıkça prosedürün çok daha hızlı ve kolay hale geldiğini vurgulamışlardır. Pediatrik zirkonyum kuronun alt süt azı dişlerine uygulanmasının, ön grup dişler veya üst süt azı dişlerine uygulamaktan daha kolay olduğunu bildirmişlerdir. Hasta kooperasyonunun uygun olması gerekliliği ve koopere olmayan hastalarda sedasyon uygulamasinın kuron uygulamasına yardımcı olabileceği ayrıca vurgulanmaktadır (45).

\section{SONUÇ}

Çocuk hastada dişlerde fazla madde kayıbı görülen durumlarda çeşitli tedavi yöntemleri geliştirilmiştir. Çocuğun yaşı, estetik ve fonksiyon ihtiyacı, maliyet, uygulama kolaylığı, tedavi süresi, restorasyon gerektiren diş sayısı gibi faktörler uygulanacak tedavi yöntemlerinin belirlenmesinde önemli kriterleri oluşturmaktadır. Ön bölgede uygulanacak bir tedavi yönteminde estetik ön planda iken, arka bölgede fonksiyon ön plana çıkmaktadır.

Pediatrik kuronlar ile ilgili yapılmış çok fazla randomize klinik çalışma bulunmamaktadır. Mevcut çalışmaların sonucuna göre paslanmaz çelik kuronlar ile zirkonyum kuronlar karşılaştırıldı ğında hasta memnuniyetinin zirkonyum kuronlarda daha fazla olduğu fakat maliyetin öne çıkması sebebiyle günümüzde halen paslanmaz çelik kuronların ve onların daha estetik hale getirilmiş olan modifikasyonlarının kullanılmaya devam ettiği bilinmektedir.

Hakem Değerlendirmesi: Dış bağımsız.

Peer Review: Externally peer-reviewed.

Yazar Katkıları: Çalışma Konsepti/Tasarım- M.K.; Veri Toplama- O.Ü.; Veri Analizi/Yorumlama- M.K., O.Ü.; Yazı Taslağ1- O.Ü.; İçeriğin Eleştirel İncelemesi-M.K.; Son Onay ve Sorumluluk- O.Ü., M.K.

Author Contributions: Conception/Design of Study- M.K.; Data Acquisition- O.Ü.; Data Analysis/ Interpretation- M.K., O.Ü.; Drafting ManuscriptO.Ü.; Critical Revision of Manuscript- M.K.; Final Approval and Accountability- O.Ü., M.K.

Çıkar Çatışması: Yazarlar çıkar çatışması beyan etmemişlerdir

Conflict of Interest: Authors declared no conflict of interest.

Finansal Destek: Yazarlar finansal destek beyan etmemişlerdir.

Financial Disclosure: Authors declared no financial support.

\section{KAYNAKLAR}

1. Petersen PE, Lennon MA. Effective use of fluorides for the prevention of dental caries in the 21st century: The who approach. Community Dent Oral Epidemiol 2004;32(5):319-21.

2. Margolis HC, Moreno EC. Composition and Cariogenic Potential of Dental Plaque Fluid. Crit Rev Oral Biol Med 1994;5:1-25.

3. Goldberg M. Deciduous tooth and dental caries. Annals Pediatr Child Health 2017;5(1):1120-25.

4. Mulder R, Medhat R, Mohamed N. In vitro analysis of the marginal adaptation and discrepancy of stainless steel crowns. Acta Biomater Odontol Scand 2018;4(1):20- 9. 
5. American Academy of Pediatric Dentistry. Guideline on Restorative Dentistry. The Ref Manual Pediatr Dent 2016;38(6):250-8.

6. Srinath S, Kanthaswamy A. Different crown used for restoring anterior primary teeth: A review. J Pharma Sci Res 2017;9(2):190-3.

7. Waggoner WF. Restorative Dentistry for the Primary Dentition. In: Pediatric Dentistry: Infancy Through Adolescence. Eds: Pinkham JR, Casamassimo PS, Fields Jr HW, McTigue DJ, Nowak AJ. St. Louis: Saunders. 4th Edition, 2005.p. 341-74.

8. Srinath S, Kanthaswamy A. Different crown used for restoring anterior primary teeth: A review. J Pharma Sci Res 2017;9(2):190-3.

9. Available from: URL:http://www.kinderkrowns. com/about-us/history/ (Erişilme tarihi: 30 Mart 2020)

10. Fellagh HF. Evaluation of full coronal esthetic restorations in primary incisors: clinical success, Parental satisfaction, In vitro fracture resistance and Bacterial adhesion. Yeditepe University, Institute of Health Sciences, Department of Pediatric Dentistry. Istanbul, 2016 p.1-224.

11. Veerakumar R, Pavithra J, Sekar K. Esthetic crown in paediatric dentistry: A review. IJIDS 2017;2(2):44-62.

12. Humphrey WP. Use of chrome steel in children's dentistry. Dental Survey 1950;26: 145-9.

13. Einwag J, Dunninger P. Stainless steel crown versus multisurface amalgam restorations: An 8-year longitudinal clinical study. Quint Inter 1996;27(5):321-3.

14. Seale NS. The use of stainless steel crowns. Pediatr Dent 2002;24(5): 501-5.

15. Alaçam T, Uzel İ, Alaçam A. Fazla madde kayıplı süt dişlerinde tedavi seçenekleri. In: Endodonti. Barıș Yayınları. Ankara. 2000.s: 571-609.

16. Atieh M. Stainless steel crown versus modified open-sandwich restorations for primary molars: A 2-year randomized clinical trial. Int J Paediatr Dent 2008;18(5): 325-32.

17. Webber DL. Gingival health following placement of stainless steel crowns. ASDC J Dent Child 1974;41(3):186-9.

18. Sharaf AA, Farsi NM. A clinical and radiographic evaluation of stainless steel crowns for primary molars. J Dent 2004;32(1):27-33.

19. Papathanasiou AG, Curzon ME, Fairpo CG. The influence of restorative material on the survival rate of restorations in primary molars. Pediatr Dent 1994;16(4):282-8.

20. Kindelan S, Day P, Nichol R, Willmott N, Fayle $\mathrm{S}$. UK national clinical guidelines in paediatric dentistry: Stainless steel preformed crowns for primary molars. Int J Pediatr Dent 2008;18(1):20-8.

21. Wiedenfeld KR, Draughn RA, Welford JB. An esthetic technique for veneering anterior stainless steel crowns with composite resin. ASDC J Dent Child 1994;61(5-6):321-6.

22. Nagarathna C, Thimmegowda U, Basavarajendrappa $\mathrm{R}$, Bhat $\mathrm{P}$. The utility of openfaced anterior stainless steel crown restoration among pediatric dentists as a lucrative esthetic option in primary incisors. J Pharma Sci 2016;5(12):156-7.

23. Wiedenfeld KR, Draughn RA, Goltra SE. Chairside veneering of composite resin to anterior stainless steel crowns: Another look. ASDC J Dent Child 1995;62(4):270-3.

24. Waggoner WF, Cohen H. Failure strength of four veneered primary stainless steel crowns. Pediatr Dent 1995;17(1):36-40.

25. Roberts C, Lee JY, Wright JT. Clinical evaluation of and parental satisfaction with resin-faced stainless steel crowns. Pediatr Dent 2001;23(1):28-31.

26. Fuks AB, Ram D, Eidelman E. Clinical performance of esthetic posterior crowns in primary molars: A pilot study. Pediatr Dent 1999;21(7):445-8.

27. Shah PV, Lee JY, Wright JT. Clinical success and parental satisfaction with anterior preveneered primary stainless steel crowns. Pediatr Dent 2004;26(5):391-5.

28. Stewart RE, Luke LS, Pike AR. Preformed polycarbonate crowns for the restoration of 
anterior teeth. JADA1974;88(1):103-7.

29. Venkataraghavan K, Chan J, Karthik S. Polycarbonate crowns for primary teeth revisited: Restorative options, technique and case reports. J Indian Soc Pedod Prev Dent 2014;32(2):156-9.

30. Nitkin DA, Rosenberg HM, Yaari AM. An improved technique for the retention of polycarbonate crowns. ASDC J Dent Child 1977;44(2):108-10.

31. Waggoner WF. Restoring primary anterior teeth. Pediatr Dent 2002;24(5):511- 6 .

32. Citron CI. Esthetics in Pediatric Dentistry. NYS Dental Journal 1995;61(2):30-3.

33. Kupietzky A. Bonded resin composite strip crowns for primary incisors: Clinical tips for a successful outcome. Pediatr Dent 2002;24(2):145-8.

34. Tate AR, Ng MW, Needleman HL, Acs G. Failure rates of restorative procedures following dental rehabilitation under general anesthesia. Pediatr Dent 2002;24(1):69-71

35. Ram D, Peretz B. Composite crown-form crowns for severely decayed primary molars: A technique for restoring function and esthetics. J Clin Pediatr Dent 2000;24(4):257- 60.

36. Daniels L, Sim M, Simon J. Plastics in pedodontics. Dent Clin North Am 1996;17:85-92.

37. Mete A. Süt azı dişlerinde CAD/CAM yöntemiyle hazırlanan kuronların in vitro şartlarda karşılaştırılması. Doktora Tezi. Erzurum: Atatürk Üniversitesi; 2014 s.3-134
38. Liu PR. A panorama of dental CAD/CAM restorative systems. Compend Contin Educ Dent 2005;26:507-8.

39. Tsitrou EA, Van Noort R. Minimal preparation designs for single posterior indirect prostheses with the use of the Cerec system. Int J Comput Dent 2008;11(3- 4):227-40.

40. Piconi C, Maccauro G. Zirconia as a ceramic biomaterial. Biomater 1999;20(1):1-25.

41. Babaji P. Different crowns used in pediatric dentistry. In: Babaji P. Crowns in Pediatric Dentistry. 1th ed. New Delhi, India: Jaypee Brothers Medical Publishers; 2015.p:23-5.

42. Denry I, Holloway JA. Ceramics for dental applications: a review. J Dent Mater 2010;3:35168.

43. Tote JV, Godhane A, Das G, Soni S, Jaiswal K, Vidhale G. Posterior esthetic crowns in pediatric dentistry. IJDMR 2015;1(6):197-201.

44. Holsinger DM, Wells MH, Scarbecz M, Donaldson M. Clinical Evaluation and Parental Satisfaction with Pediatric Zirconia Anterior Crowns. Pediatr Dent 2016;38(3):192-7.

45. Lopez Cazaux S, Hyon I, Prud'homme T, Trutaud SD. Twenty-nine-month follow-up of a paediatric zirconia dental crown. BMJ Case Rep 2017:bcr2017219891. 
